\title{
1. Introduction: innovation and education matters in European entrepreneurship research
}

\section{Ulla Hytti, Robert Blackburn and Eddy Laveren}

\section{INTRODUCING THE CHAPTERS}

The title of our introductory chapter to this volume in the Frontiers in European Entrepreneurship Research series can be interpreted in two ways. First, it illustrates that the volume pays attention to two enduring areas in entrepreneurship research - innovation and education. Second, it highlights the importance of both innovation and education for future economic and societal development. In contemporary societies and economies, it is important to focus research on innovation and education, as these activities matter as significant factors in economic and social development.

Innovation is acknowledged as a major factor contributing to the performance, growth and competitiveness of firms and economies. Yet, research on innovation at the firm level has been either focused on a very narrow section of new and small ventures - high-technology firms (Gabrielsson et al., 2014) - or been studied in the context of large and listed firms. De Massis and Rovelli have, therefore, an important ambition in extending the field to studying innovation also in the context of family firms and small and medium-sized enterprises (SMEs) in Chapter 2. They base their argument on the fact that family firms and SMEs are the most diffused organizational forms around the world, as well as the view that family firms and SMEs have their own distinctive characteristics. Our understanding of innovation may be limited and incomplete if our research is not extended to also cover family firms and SMEs. If family firms and SMEs increasingly participate in innovation activities, their economic and social impact will be important. In their chapter the authors highlight relevant research avenues and develop several research questions that will help to call and pave the way for future research on innovation in family and SMEs. 
In Chapter 3, Jørgensen and Mathisen address this call by investigating the innovation process in a manufacturing SME. Besides this they focus on another neglected element in innovation research, that of the rural context. The authors argue that speed of innovation (elapsed time between an initial discovery and its commercialization) is important for rural SMEs that cannot draw competitive advantages from economies of scale or competing on price. Being innovative and able to launch their new products or services on the market quickly is often the only way to create competitive advantage. The authors use a qualitative single-case study to study the speed in the development phase and the launching phase through retrospective informant stories. The main findings highlight that dimensions, degree and dynamics of proximity in relationships to external actors influence speed of innovation. For SMEs in rural contexts, geographical proximity varies across the different phases and actors, and is a foundation for the development of social and cognitive proximity. For example, geographical proximity is found crucial in the idea generation phase, to speed up the innovation process, whereas institutional and/or cognitive proximity enabled good knowledge interactions with universities and researchers. The authors find that social proximity (trust and good relations) is important to implement the opportunity potential in terms of cognitive proximity (mutual understanding and knowledge base that facilitates communications).

Rural context is also highlighted in Chapter 4 by Aylward, Reinl and Kelliher. The chapter investigates micro firm community learning in a rural tourism context. Micro firms are a predominant form of business activity in rural contexts but they often suffer from lack of resources, isolation issues and market challenges. However, the authors argue that learning with others can assist them to remain competitive and to overcome sizespecific resource constraints, isolation and market challenges. The chapter identifies three key influences on sustained learning community activity using a multi-case study methodology. The first reflects the requirement for a balanced and regularly replenished broker to promote autonomy in this environment. The second emphasizes a need for progressive strategies tailored to the life cycle of the learning community. Finally, the case findings illustrate how boundary interactions influence knowledge flows and competence development in support of learning community goals. The authors acknowledge that more research is needed on the support actors as to their value for learning communities. Competent brokerage is not yet fully understood by community stakeholders.

European entrepreneurship research is all about context (Hytti et al., 2018) and, as well being exemplified in Chapters 3 and 4, is illuminated further in Chapter 5. In this chapter, François, Lafaye and Belarouci 
adopt a contextual approach to social capital in a study focusing on innovative firms and antecedents of business performance. The authors investigate 104 founder-owner entrepreneurs from innovative SMEs that have received public support and examine the role of social capital in the growth of innovative firms in their first years of development. During the early years young ventures seem to benefit from external social capital as opposed to internal social capital. This is explained by the young age and small number of employees in these firms but the impact of internal social capital increases once the firms reach a certain size threshold. Moreover, while belonging to a cluster (or 'pôle de compétitivité') impacts on growth, the study finds no significant impact of clusters on the link between social capital relations and growth. Interestingly, the analysis does not support the notion that firms which have passed through an incubator have a greater level of external social capital, subsequently ensuring better growth. The authors call for additional research measuring the effects of public support.

In Chapter 6, Joensuu-Salo, Sorama and Kettunen contribute to research on antecedents to business performance and success by focusing on market orientation (i.e. how to acquire and use knowledge and understanding of customers and competitors); and marketing capability (i.e. skills and knowledge to create solid relationships with customers, distributors and suppliers). The chapter analyses the impact of market orientation and marketing capability on business performance in SMEs in the forest industry, including if the impact is different in domestic and international SMEs. By drawing on survey data from 504 SMEs in Finland, the analysis suggests that both market orientation and marketing capability have an impact on business performance of Finnish SMEs but this impact is more pronounced in firms operating in international markets than those operating only in domestic markets. The findings also suggest that market orientation has an impact on marketing capabilities and, indirectly, on business performance. The authors thus suggest it is important for SMEs to develop their market orientation which in turn develops their marketing capabilities to increase firm's success.

The second main theme in this volume is education. Entrepreneurship education is seen as a key ingredient in developing entrepreneurial potential among students (Guerrero and Urbano, 2015; Varamäki et al., 2016). However, an important discussion in entrepreneurship education research is what and how to teach entrepreneurship. It is acknowledged that there is no simple, or single, solution but various approaches are linked to the different aims of entrepreneurship education. Aadland and Aaboen contribute to this discourse in Chapter 7 by developing a new typology for entrepreneurship education based on a structured review of the literature 
in the field. Their typology comprises six different approaches to entrepreneurship education, consisting of the objectives and learning activities. They separate the learning approaches into three different categories of student involvement: passive (lectures), participative (input/output focused) and self-driving focus on methods used. Furthermore, the authors separate the objectives into 'student-centred impact' and 'contextual impact', based on the influence from the education on external stakeholders. Compared with previous typologies, their new typology allows for a more nuanced distinction based on the students' learning activity and the educational impact in terms of time and external contact and influence. The typology moves the focus from teacher-centred to student-centred understanding. The chapter has the ambition of enabling cumulative research in the growing field of entrepreneurship education.

The bulk of entrepreneurship education research has focused on students, which neglects any understanding of entrepreneurship education from the teacher's perspective or in the teacher's education. This is surprising given the importance of teachers in educational contexts where they have an important role in facilitating and influencing knowledge creation of learners. Axelsson and Westerberg address this gap in Chapter 8 where they study how entrepreneurship is conceptualized and designed in teacher education programmes. The chapter is informed by a qualitative case study of a Swedish teacher education entrepreneurship module, for elementary and secondary teachers, applying inquiries and group interviews with students and semi-structured interviews with teachers. The chapter makes use of Fayolle and Gailly's (2008) teaching model framework as an analytic lens to provide necessary understanding in relation to the pedagogical and didactic questions. The analysis shows how entrepreneurship education in teacher education is riddled with tensions relating to overall mission, target groups, pedagogy, content and assessments. However, there are paths forward that might mitigate these tensions and provide a better opportunity for entrepreneurship education development within the realm of teacher education. The chapter gives new insights on how entrepreneurship can be included in a teacher education programme and address potential tensions. The chapter also highlights the need to understand both the teacher education students and their future pupils, as the target groups in entrepreneurship education development, and allow the teacher education students to search for their role and to create their own knowledge base in entrepreneurship education.

Entrepreneurship education research has also been dominated by investigation into formal education and, consequently, ample knowledge is derived from different types of modules or pedagogies in entrepreneurship education. However, since different kinds of student societies play an 
important role as the informal learning arenas for university students - and in entrepreneurship in particular - it is more than welcome that Parkkari and Kohtakangas investigate student Entrepreneurship Societies in Chapter 9. The chapter aims to develop a better understanding of student entrepreneurship society organizations. Using ethnography, the chapter shows how these organizations were constructed as a student movement, aiming to awaken students' entrepreneurial latencies through practices enacted during a weekend-long get-together event of 40 participants. The observed practices included little space for negotiating the meaning of entrepreneurship or why it is promoted. Multiple ideals emerged, such as valuing the practices of 'doing', while aiming to stay clear of 'politics'. The findings indicate that the phenomenon of Entrepreneurship Societies reflects the dispersion and power of entrepreneurship discourse and ideology. The chapter contributes to the new, emerging research area of entrepreneurship-as-practice.

Finally, in Chapter 10, Markowska and Welter focus on identity construction which may also be seen as highly applicable to entrepreneurship education practices. They understand entrepreneurial identities as emergent and developed through interaction with various actors, and are interested in their changing motivations and goals upon maturing. The authors analyse seven high-profile restaurateurs' business lives and show how their stories have been reinvented over time. Three different narratives are employed to illustrate the entrepreneurs' original career choices: dream follower, serendipitous craftsman and forced opportunist. By demonstrating how achievement motivation affects restaurateurs' need to either belong or be distinct, and thus their construction of their narrative entrepreneurial identity, the research enhances existing work on identity construction by highlighting the close relationship between restaurateurs' career stage and their emphasis on either the need for belonging or the need for distinctiveness. The authors extend our understanding of the entrepreneurial identity construction process, by linking motivation and identity and by showing how this relationship evolves over time. To be more precise, the research finds that while restaurateurs' early identities centre on presenting themselves as chefs, their subsequent narrations are wrapped up in their social identity in a broader sense and not limiting them to a particular role.

\section{OUTLOOK}

Overall, this anthology offers varied and novel insights on our understanding of innovation in different contexts and entrepreneurship education. 
More particularly, the chapters contribute to highlighting the need for research in innovation and learning in family firms, micro firms, and in rural and network contexts. In addition, the chapters offer new insights into the antecedents of business performance in SMEs, especially in the form of social capital and marketing capabilities. The chapters also offer new insights, conceptual and empirical, of entrepreneurship education research: an area of growing importance within entrepreneurship research more broadly. Hence, the chapters offer a new typology for analysing entrepreneurship education programmes, discussing opportunities for embedding entrepreneurship in teacher education and exploring entrepreneurship in the informal learning arenas in universities. Finally, by focusing on identity construction new insight is developed on the motivations of the individual in the entrepreneurship process. Collectively, the chapters illustrate the contextual embeddedness, methodological diversity and prevalent distinctive clusters that we have come to associate with European entrepreneurship research (Hytti et al., 2018).

\section{REFERENCES}

Fayolle A. and B. Gailly (2008), 'From craft to science: Teaching models and learning processes in entrepreneurship', Journal of European Industrial Training, 32 (7), 569-93.

Gabrielsson, J., D. Politis and A. Lindholm Dahlstrand (2014), 'Entrepreneurship and technological innovation: The influence of uncertainty and entrepreneurial ability on innovation speed in new technology start-ups', in R. Blackburn, F. Delmar, A. Fayolle and F. Welter (eds), Entrepreneurship, People and Organisations: Frontiers in European Entrepreneurship Research, Cheltenham, UK and Northampton, MA, USA: Edward Elgar Publishing, pp. 116-35.

Guerrero, M. and D. Urbano (2015), 'The effect of university and social environments on graduates' start-up intentions: An exploratory study in Iberoamerica', in R. Blackburn, U. Hytti and F. Welter (eds), Context, Process and Gender in Entrepreneurship: Frontiers in European Entrepreneurship Research, Cheltenham, UK and Northampton, MA, USA: Edward Elgar Publishing, pp. 55-86.

Hytti, U., R. Blackburn and S. Tegtmeier (2018) 'Introduction: Establishing new frontiers for European entrepreneurship research', in U. Hytti, R. Blackburn and S. Tegtmeier (eds), The Dynamics of Entrepreneurial Contexts, Frontiers in European Entrepreneurship Research, Cheltenham, UK and Northampton, MA, USA: Edward Elgar Publishing, pp. 1-21.

Varamäki, E., S. Joensuu-Salo and A. Viljamaa (2016), 'The intention-behavior link of higher education graduates', in U. Hytti, R. Blackburn, D. Fletcher and F. Welter (eds), Entrepreneurship, Universities \& Resources: Frontiers in European Entrepreneurship Research, Cheltenham, UK and Northampton, MA, USA: Edward Elgar Publishing, pp. 146-67. 